\title{
Oleaginous crops as integrated production platforms for food, feed, fuel and renewable industrial feedstock
}

\section{Manipulation of plant lipid composition via metabolic engineering and new opportunities from association genetics for crop improvement and valorisation of co-products}

\author{
Frédéric Beaudoin $^{1, \star}$, Olga Sayanova ${ }^{1}$, Richard P. Haslam ${ }^{1}$, Ian Bancroft ${ }^{2}$ and Johnathan A. Napier ${ }^{1}$ \\ 1 Department of Biological Chemistry and Crop Protection, Rothamsted Research, Harpenden, Herts, AL5 2JQ, UK \\ 2 CNAP, Department of Biology, University of York, Heslington, YO10 5DD, UK
}

Received 25 September 2014 - Accepted 6 October 2014

\begin{abstract}
The world faces considerable challenges including how to produce more biomass for food, feed, fuel and industrial feedstock without significantly impacting on our environment or increasing our consumption of limited resources such as water or petroleum-derived carbon. This has been described as sustainable intensification. Oleaginous crops have the potential to provide renewable resources for all these commodities, provided they can be engineered to meet end-use requirements, and that they can be produced on sufficient scale to meet current growing world population and industrial demand. Although traditional breeding methods have been used successfully to modify the fatty acid composition of oils, metabolic engineering provides a more rapid and direct method for manipulating plant lipid composition. Recent advances in our understanding of the biochemical mechanisms of seed oil biogenesis and the cloning of genes involved in fatty acid and oil metabolic pathways, have allowed the generation of oilseed crops that produce 'designer oils' tailored for specific applications and the conversion of high biomass crops into novel oleaginous crops. However, improvement of complex quantitative traits in oilseed crops remains more challenging as the underlying genetic determinants are still poorly understood. Technological advances in sequencing and computing have allowed the development of an association genetics method applicable to crops with complex genomes. Associative transcriptomics approaches and high throughput lipidomic profiling can be used to identify the genetic components controlling quantitative variation for lipid related traits in polyploid crops like oilseed rape and provide molecular tools for marker assisted breeding. In this review we are citing examples of traits with potential for bio-refining that can be harvested as co-products in seeds, but also in non-harvested biomass.
\end{abstract}

Keywords: Crops improvement / oleaginous crops / metabolic engineering / designer oil / molecular breeding / Genome Wide Association Studies / associative transcriptomics / co-products

Résumé - Les oléagineux en tant que plateformes intégrées de production pour l'alimentation humaine et animale, les carburants et les matières premières industrielles renouvelables : Manipulation de la composition lipidique de la plante par ingénierie métabolique et nouvelles opportunités d'associations génétiques pour l'amélioration des cultures et la valorisation des coproduits. Le monde fait face à des défis considérables, incluant le moyen de produire davantage de biomasse pour l'alimentation humaine et animale, les carburants et les matières premières industrielles, et ce sans impact environnemental significatif ou sans accroître notre consommation de ressources limitées comme l'eau ou le carbone dérivé du pétrole. Cela a été décrit comme de l'intensification durable. Les oléagineux disposent du potentiel nécessaire pour fournir des ressources renouvelables pour toutes ces matières premières, sous réserve qu'ils puissent être manipulés de manière à respecter les exigences d'utilisation finale et qu'ils puissent être produits à une échelle suffisante, répondant ainsi à une pression démographique mondiale et à une demande industrielle croissantes. Bien que des méthodes de reproduction traditionnelles aient été utilisées avec succès pour modifier

^ Correspondence: frederic.beaudoin@arothamsted.ac.uk 


\begin{abstract}
la composition en acides gras des huiles, l'ingénierie métabolique fournit une méthode plus rapide et plus directe pour manipuler la composition en lipides des végétaux. Des avancées récentes dans notre compréhension des mécanismes biochimiques de biogenèse d'huile dans les graines et le clonage de gènes impliqués dans les voies métaboliques des acides gras et huiles, ont permis la génération d'oléagineux produisant des «huiles sur mesure », adaptées à des demandes spécifiques et la conversion de variétés à haut potentiel de biomasse en nouvelles variétés oléagineuses. Cependant, l'amélioration de caractères quantitatifs complexes chez les oléagineux demeure difficile, les déterminants génétiques sous-jacents étant toujours mal compris. Néanmoins, des avancées technologiques dans le séquençage des acides nucléiques et le traitement informatique ont permis le développement d'une méthode de génétique d'association applicable aux plantes ayant des génomes complexes. Ainsi, des approches de transcriptomiques associatives et de profilage lipidomique à haut débit peuvent être utilisées afin d'identifier les composants génétiques contrôlant la variation quantitative de caractères liés aux lipides chez les plantes polyploïdes comme le colza, et de fournir des outils moléculaires pour la sélection assistée par marqueur moléculaire. Dans cette revue, nous citons des exemples de caractères présentant un potentiel pour le bioraffinage qui peuvent être récoltés comme des coproduits dans les graines, mais aussi dans la biomasse non-récoltée.
\end{abstract}

Mots clés : Amélioration des plantes / plantes oléagineuses / ingénierie métabolique / huiles specialisées / Études d'association pangénomique / Études association trancriptomique / Co-produits

\section{Introduction}

Currently, global oilseed production is of the order of $450 \mathrm{Mt} / \mathrm{year}$, with that figure predicted to rise to $500 \mathrm{Mt}$ by 2020 (OECD-FAO data). Mirroring these figures, the current and projected consumption rates closely track these numbers, meaning that supply can barely keep pace with demand. As the human population continues to increase, and historical patterns of consumption are changed and expanded as a consequence of increased economic affluence, the need for even greater levels of oilseeds and renewable oil is inexorable. This situation is complicated by both regional aspects of different oilseed crops (in terms of agronomy, processing and end-user supply chain) and more global fluctuation in demands for a given specific vegetable oil. Finally, there is the continued dilemma of having a finite amount of land available for agriculture, with the added complication of the ongoing "food versus fuel" debate of how best to use this limited resource. All of these factors point towards the need for more efficient production of crops, delivered in tandem with optimised traits for both primary and co-products. This review will consider the approaches being adopted to address these challenges, as well as highlighting some emerging topics which may also play a role in the future.

\section{Current and new oleaginous crop platforms}

Over the last two decades the majority of increased vegetable oil production has been met by four oil crop platforms: oil palm (Elaeis guineensis), soybean (Glycine max), rapeseed (Brassica napus) and sunflower (Helianthus annuus). There has been a striking growth in oil palm production over recent years (Carlsson, 2009). Oil palm fruit, renowned for its exceptional oil yields, has a fleshy mesocarp surrounding a hardened endocarp that contains a large seed or kernel (approximately $85 \%$ and $50 \% \mathrm{w} / \mathrm{w}$ oil content, respectively). The two oils (palm and kernel) are of major economic importance and have different compositions. While medium-chain fatty acids (C8$\mathrm{C} 14)$ predominate in the endosperm, the mesocarp oil contains primarily palmitic acid (16:0) and oleic acid (18:1). Soybean is the most important legume in the world, mostly grown for the quality of its protein; the bean also contains oil $(\sim 20 \% \mathrm{w} / \mathrm{w})$.
For such a significant agricultural crop, an extensive breeding and genomics knowledge base has been generated enabling the development of additional oil qualities e.g. higholeic, high palmitic and high stearic acids (Dyer and Mullen, 2005). Rapeseed is the third largest oil crop in terms of production. The seeds of the best oilseed rape cultivars contain 45$50 \%$ oil (w/w) at maturity. Traditionally rapeseed contained a high level of erucic acid (22:1) however, the majority of varieties in cultivation today are based on a zero erucic acid background (Canola). Rapeseed oils are used extensively for food applications as well as feedstock, e.g. biodiesel. Sunflower is widely adapted to temperate climates and is more drought tolerant than many grain crops. The final oil content of sunflower seeds is usually around $50 \% \mathrm{w} / \mathrm{w}$. The extracted oil is rich in linoleic acid (18:2 n-6; 48\% to 74\%). It also contains low levels of saturated fatty acids and unlike soybean and rapeseed, negligible amounts of $\alpha$-linolenic acid (18:3n-3). The relative amount of linoleic compared to oleic acid is variable and is related to temperature regulation of endogenous desaturases.

The importance of these four crop platforms in global oil production is substantial. However, such is the increasing demand for vegetable oils that new or underutilized oilseed crops that are more suited for cultivation on less fertile land or in arid and semi-arid climates that do not support production of major oilseed crops, have been introduced. In addition, production of inedible oils containing unusual fatty acids and designed to be used as industrial feedstock should be confined to dedicated non-food crop platforms to minimize the risk of out-crossing and prevent introduction into the food chain. A number of oilseeds have recently received attention for their potential to fill one or more of these niches. These include the Brassicaceae species Ethiopian mustard (Brassica carinata), crambe (Crambe abyssinica), and camelina (Camelina sativa) as well as the Euphorbiaceae species jatropha (Jatropha curcas). These oilseeds have specific qualities e.g. unusual fatty acid synthesis, agronomic performance or molecular tractability that enables the production of technical oils to be accomplished and transformation methods have been reported for all of them (Lu et al., 2011). However, as will be discussed in this review, camelina has emerged as a particularly attractive new platform for metabolic engineering. Recently, the possibility of producing oil in vegetative tissue has also attracted attention 
to high-biomass crops such as tobacco as alternative platforms for renewable oil production (Vanhercke et al., 2013). Tobacco (Nicotiana tabacum) can produce over 20 tons of dry biomass per hectare and it has been suggested that it could be engineered to produce oil yield comparable to oil palm (Carlsson et al., 2011; Vanhercke et al., 2013). An oil producing tobacco crop could therefore be used for fuel production but other edible/non-toxic biomass crops such as corn (Zea mays) or miscanthus (Miscanthus giganteus) could be engineered for use as a high energy fodder or for energy production.

\section{Manipulation of plant lipid composition and content for specialised oil and high energy biomass production}

\subsection{High oleate rapeseed and sunflower}

Oleic acid enhancement of vegetable oils has been a major biotechnological target. Oils enriched in oleic acid have improved oxidative stability for food processing as well as biofuel and bio-based products. These oils have also been in increasing demand for use in foods with hydrogenated oils that are low in trans-fats. High oleic acid phenotypes have been achieved primarily by seed-specific suppression of Fatty Acid Desaturation 2 (FAD2), which encodes the first enzyme committed to Polyunsaturated Fatty Acids (PUFAs) biosynthesis, and therefore blocking the desaturation pathway. Conventional breeding has produced inactivating mutations in up to three of the four FAD2 orthologues present in B. napus, resulting in winter oilseed rape cultivars like Cabriolet showing reduced PUFA content (oil profile: 75\% 18:1, 16\% PUFAs). Recently, very high oleic and very low PUFAs rapeseed lines (oil profile: $\sim 84 \% 18: 1,6 \%$ PUFAs) that also carry mutations in the remaining functional copy have been generated using chemical mutagenesis (Wells et al., 2014). Other recent reports suggest that further increases in oleic acid content in oils could be achieved following a strategy of seed-specific enhancement of acyl-CoA:diacylglycerol acyltransferase (DGAT) activity (Banaś et al., 2013).

Many lines of sunflower with modified fatty acid composition have been produced over the years. The most successful development has been the production of high or ultra-high oleic mutants, which produce oils with fatty acid compositions similar to olive oil ( 70-90\% 18:1). The other alternative vegetable oil for industrial processes is palm oil; however palm oil is rich in palmitate. Palm oil has been extensively used for human nutrition, despite some controversy as to whether high dietary palmitic acid can have an effect on plasma lipoproteins. No such potentially negative effects have been attributed to stearic acid. However, the original high stearic sunflower lines also contain high levels of linoleic acid, which diminishes its utility i.e. stability at high temperatures. A situation resolved by transferring the high stearic phenotype to high oleic lines to obtain the high stearic-high oleic (HSHO) mutant, commercialized as Nutrisun oil@. The high stearic-high oleic oils can be used in a broad variety of food formulations and demonstrated to be an alternative to palm oleins for industrial frying, with good stability and high vitamin content (Salas et al., 2014).
Utilization of the rapeseed and sunflower lines described above for production of oil and fat for the industry has the advantages of avoiding any use of GMO and therefore the legal requirement in Europe and many Asian countries to label food to declare the presence of transgenic material.

\subsection{High erucate rapeseed and crambe}

Erucic acid and its derivatives are important for manufacturing plastics and high temperature lubricants. Erucic acid is currently mainly derived from high erucic acid rapeseed (HEAR with $\sim 50 \%$ 22:1 in seed oil) which were obtained by conventional breeding. However, HEARs cross easily with existing rapeseed and can be inadvertently mixed, hampering the development of HEARs in many countries. Genetically modified rapeseed with a significant increase (over 70\%) in erucic acid has been developed (Nath et al., 2009), but strict legislation in Europe has restricted its utility and as discussed above, a food crop oilseed rape is not the most suitable platform for engineering industrial feedstocks. Crambe, a member of the Brassicaceae, is more suitable for genetic engineering and already contains $60 \% 22: 1$ in its seed oil. Using a gene stacking strategy, overexpression of a lysophosphatidic acid acyltransferase (LPAAT) and a fatty acid elongase 1 (FAE1), whilst down-regulating $F A D 2$, resulted in lines with substantially higher levels of 22:1 (77\%) compared to wild type ( $\mathrm{Li}$ et al., 2012; Guan et al., 2014). Crambe does not outcross with conventional oilseed crops, is already commercially cultivated on a small scale, and novel varieties can yield the same amount of oil per hectare as spring oilseed rape suggesting that genetically modified crambe could be adopted in regular agricultural practice.

\subsection{Metabolic engineering of novel oil traits in Camelina sativa}

Research on the metabolic engineering of oil-related traits has largely depended on the model oilseed Arabidopsis. However, interest has grown in demonstrating these traits in established oilseed crops. For the production of speciality oils, attention has focused on camelina (Camelina sativa (L.) Crantz), a re-emergent oilseed crop that is also becoming important as a model for applied projects based on studies in Arabidopsis thaliana, since the two species are closely related members of the Camelineae tribe of Brassicaeae (Julie-Galau et al., 2014). Camelina has emerged as an attractive host for metabolic engineering because it can be easily transformed using an Agrobacterium-based floral infiltration (Lu and Kang, 2008). Several other characteristics of Camelina contribute to the rising interest in its use: the oil content of camelina ranges from 28 to $40 \%$ with storage proteins making up a further $30 \%$; a relatively short life cycle, good performance on marginal land (yields surpass other oilseed crops under drought-like conditions); low requirement for nutrients and a low seeding rate (Nguyen et al., 2013; Napier et al., 2014). To facilitate genetic improvement the genome of camelina has now been sequenced revealing an overall expansion of lipid metabolism gene families (217\% compared with Arabidopsis) and suggesting that complex regulatory mechanisms govern oil biosynthesis (Kagale et al., 2014). The modification of 
Camelina oil composition offers great potential for industry and nutrition.

\subsubsection{Camelina as an alternative oilseed crop platform for high oleate oil production}

As previously discussed, for many industrial applications it is desirable to increase oleic acid and decrease the PUFAs content to improve oil oxidative stability. High oleic, low-PUFA camelina oils have also been generated by down-regulating the $F A D 2$ in camelina seeds through mutagenesis or genetic engineering. Seed-specific antisense suppression of $F A D 2$ by Kang et al. (2011) resulted in transgenic lines with up to $\sim 50 \%$ oleic acid and reduced PUFA content $(\sim 17 \%)$ compared with wild type although no reduction in the content of C20 and C22 fatty acids was observed. An alternative RNAi approach was used to knock down expression of FAD2 and FAE1 in Camelina seeds (Nguyen et al., 2013). This strategy resulted in the production of camelina oils accumulating up to $70 \%$ oleic acid and double FAD2/FAE1 RNAi seeds contained only about $12 \%$ PUFAs compared to $53 \%$ in wild-type seeds. In addition, C20 and C22 fatty acids were reduced from $\sim 17 \%$ of total fatty acids in wild-type seeds to $\sim 4 \%$ in FAD2/FAE1 RNAi lines. In the context of the "land for food or fuel" debate, and because of its good agronomic performance on marginal land, camelina provides a sensible alternative to rapeseed for production of oleic acid as industrial feedstock.

\subsubsection{Oil enriched in omega-7 monounsaturated fatty acids}

Oils containing omega-7 unsaturated fatty acids, primarily palmitoleic acid $\left(16: 1 \Delta^{9}\right)$, are uncommon in plant seeds. However, vegetable oils with high omega-7 monounsaturated fatty acid (MUFAs) content have improved qualities for biodiesel, namely enhanced oxidative stability, nitrogen oxides (NOx) emission and ignition quality. Omega-7 fatty acids also have value as a feedstock for polyethylene production. A strategy for increased production of omega-7 MUFAs in camelina, via the redirection of metabolic flux from typical $\Delta^{9}$ desaturation of stearoyl-acyl carrier protein (ACP) to $\Delta^{9}$ desaturation of palmitoyl-ACP, resulted in the formation of $\sim 17 \%$ omega-7 fatty acids in seed oil (Nguyen et al., 2014). Further suppression of 3-keto-acyl-ACP synthase II (KASII) and 16:0-ACP thioesterase $(F a t B)$ genes increased seed omega-7 fatty acid accumulation to $60-65 \%$ (of which $32 \%$ were $16: 1 \Delta^{9}$ ). These results demonstrate some of the highest levels of novel fatty acids generated in an oilseed crop.

\subsubsection{Toward production of hydroxy fatty acids in camelina}

Producing hydroxy fatty acids (HFA) in oilseed crops has been a long-standing research objective as a renewable source for industrial applications. The main commercial source of HFA is the castor plant (Ricinus communis), which accumulates nearly $90 \%$ ricinoleic acid $(18: 1 \mathrm{OH})$ in its seed triacylglycerols. Castor is thought unsuitable for large scale agricultural production due to the presence of the toxin ricin and highly allergenic $2 \mathrm{~S}$ albumins in its seeds. Another potential source of HFA is lesquerella (Physaria fendleri), which accumulates $60 \%$ lesquerolic acid (20:1OH). Compared to the levels of ricinoleic acid accumulation in castor, the expression of castor oleate $\Delta^{12}$-hydroxylase $(R c F A H)$ in Arabidopsis yielded disappointing results, with levels of $17 \%$ or less. The major bottleneck for HFA accumulation was hypothesised to be that native species had co-evolved unusual fatty acid accumulation and triacylglycerol assembly pathways. Arabidopsis expressing RcFAH in combination with castor DGAT, phospholipid:diacylglycerol acyltransferase or phosphatidylcholine:diacyl-glycerol acyltransferase (PDAT) more effectively moved HFAs from the site of synthesis in phosphatidylcholine to storage via triacylglycerol assembly (van Erp et al., 2011). Intriguingly, the expression in Arabidopsis of the castor acyltransferases not only increased HFA content, but also at least partially relieved the feedback inhibition of fatty acid synthesis often associated with oilseed metabolic engineering (Bates et al., 2014) and restored levels of triacylglycerol (TAG) accumulation. Production of HFAs has now been achieved in camelina, but the expression of $R c$ $F A H$ yielded only $15 \%$ HFA in seed oil, much lower than that found in castor bean. Furthermore, the seeds had a much lower seed oil content. However, HFA accumulation significantly increased (up to $\sim 20 \%$ ) with the co-expression of $R c F A H$ and a Lesquerella condensing enzyme (LfKCS3) (Snapp et al., 2014). The authors speculated that the elongation reaction may facilitate the flux of HFAs from phosphatidylcholine (PC), the site of HFA formation, into the acyl-CoA pool for more efficient utilization in triacylglycerol (TAG) biosynthesis. The oil content and seed germination also appeared normal compared to wild type. These results are encouraging and demonstrate the feasibility of engineering higher HFA-containing oils in an agriculturally amenable oilseed crop, however, the levels achieved so far remain too low to provide an economically viable alternative to castor oil.

\subsubsection{Fish oil (omega-3 LC-PUFAs) production in Camelina}

It is now well established that omega-3 long-chain polyunsaturated fatty acids (LC-PUFAs), especially eicosapentaenoic acid (20:5 n-3, EPA) and docosahexaenoic acid (22:6 n-3, DHA) have critical roles in human health and nutrition. Although the main dietary source of EPA and DHA is currently marine fish, depletion of wild fish stocks, pollution of the marine environment and the expansion of the aquaculture industry directed research efforts towards the development of alternative sustainable sources of LC-PUFAs. Metabolic engineering of the omega-3 LC-PUFA biosynthetic pathways into transgenic oilseeds represents an appealing approach to the terrestrial production of these "marine" oils. Genes encoding primary LC-PUFA biosynthetic activities, namely fatty acid desaturases (DES) and elongases (ELO) have been identified in a wide range of organisms and were initially functionally characterised in model organisms (for review see Haslam et al., 2013). Despite early successes reconstituting omega-3 and omega-6 LC-PUFA biosynthetic pathways in yeast (Beaudoin et al., 2000; Domergue et al., 2003; Meyer et al., 2004) attempts to introduce these pathway in plants 
proved to be much more challenging and resulted in disappointingly low accumulation of arachidonic acid (20:4 n-6, AA) and EPA in seeds (Abbadi et al., 2004). This was shown to be essentially the consequence of desaturase and elongase enzymes using different substrates, phospholipid-linked fatty acyl chains and acyl-CoAs respectively (Domergue et al., 2003; Abbadi et al., 2004), and was described as a "substrate dichotomy" bottleneck (Napier, 2007). As a consequence, the inefficient flux of LC-PUFAs intermediates between membrane lipids and the acyl-CoA pool resulted in rate limiting amounts of substrates available for PUFA elongation. One solution that has been proposed to bypass this metabolic bottleneck is the use of acyl-CoA-dependent desaturases. Overexpression of Ostreococcus tauri 46-desaturase (Domergue et al., 2005) in transgenic camelina resulted in the accumulation of high levels of $\Delta 6$-desaturated fatty acids with $18 \% \gamma$-linolenic acid (18:3 n-6, GLA) and 12\% stearidonic acid (18:4 n-3, SDA) (Sayanova et al., 2011). The total level of non-native $\Delta 6$-desaturated fatty acids ( $30 \%$ of seed oil) was about twice that achieved using the same construct in Arabidopsis and compared well with previous attempts to synthesize these fatty acids in transgenic soybean (Sato et al., 2004; Eckert et al., 2006) and Brassica juncea (Hong et al., 2002) using phospholipid-dependent $\Delta 6$-desaturase activities. The potential of using acyl-CoA-dependent desaturases to enhance LC-PUFA production in camelina seeds was subsequently demonstrated. The results confirmed the benefits of using such activities not only to elevate EPA accumulation but also to reduce accumulation of undesirable intermediates such as omega-6 fatty acids (Sayanova et al., 2011).

Camelina is a particularly suitable host for engineering omega-3 LC-PUFA biosynthetic pathways because it accumulates high levels of $\alpha$-linolenic acid (18:3 n-3, ALA), the starting point for biosynthesis of these important fatty acids. Recently, Ruiz-Lopez et al. (2014) demonstrated that camelina may be successfully engineered to accumulate high levels of EPA and/or DHA in its seed oil. This required the addition of multiple omega-3 LC-PUFA biosynthetic genes and coordinated tissue-specific expression in developing seeds. Two constructs (RRES_EPA and RRES_DHA) encoding the primary omega-3 LC-PUFA biosynthetic activities under the control of independent seed-specific promoters were introduced into camelina. RRES_EPA was a five genes construct designed to produce high levels of EPA in seeds while RRES_DHA was designed to accumulate both EPA and DHA and contained seven genes. As a result, seeds of RRES_EPA lines contained up to $31 \%$ EPA, and RRes_DHA seeds accumulated up to $12 \%$ EPA and 14\% DHA. These total omega-3 LC-PUFA levels of $\sim 25 \%$ are equivalent to those in fish oils, and were achieved with very low accumulation of omega- 6 intermediates. Importantly, significant levels of EPA and DHA were present in a high proportion of the T2 seeds analysed from selected lines. DHA-producing transgenic camelina lines, transformed with a suite of omega-3 LC-PUFA biosynthetic genes from several microalgal strains, have also been recently reported by Petrie et al. (2014). A construct previously transformed in Arabidopsis as well as two modified versions designed to increase DHA production were used for camelina transformation. This study reported the production of fish oil-like levels of DHA $(\sim 12 \%)$ in seeds and a high n-3/n-6 ratio. DHA was found to be stable to at least T5 generation and EPA and DHA were found to be predominantly at the sn- 1 and sn- 3 positions of triacylglycerols. In both studies transgenic and parental lines did not have different germination or seedling establishment rates. These studies clearly demonstrate camelina's potential as a sustainable source of omega-3 LC-PUFAs, and represents a breakthrough in the search for a sustainable alternative production platform for these marine fatty acids.

\subsubsection{Wax esters production in camelina as a renewable source of biolubricants}

Wax esters (WE) are esters of long chain fatty acids and fatty alcohols which are commercially very important and are produced on a scale of 3 million tons per year (Kalscheuer et al., 2006). They have a multitude of important technical applications in a variety of areas, including medicine, cosmetics, and food industries, as well as their more traditional usage as lubricants. Wax esters have lubrication properties that are superior to ordinary vegetable oil, i.e. triacylglycerols (TAGs), due to their high oxidation stabilities and resistance to hydrolysis. The main natural sources of wax esters are the protected sperm whale (spermaceti oil) and jojoba, a low yield desert shrub not amenable to sustainable agricultural practices. The type of application for wax esters depend on their physical properties and therefore on their composition. For example Spermaceti, which consists principally of saturated WEs with 28 and 36 carbon chains and has a freezing point around $30{ }^{\circ} \mathrm{C}$, was used as a gear box lubricant by the car industry at the beginning of the 20th century. This unique combination of medium chain lengths and very low desaturation of esters conferred to Spermaceti suitable viscosity and very high stability at ambient temperatures. In contrast, liquid wax esters from the jojoba have a carbon chain length of $\mathrm{C} 36$ to C48 and are composed mainly of C20:1 fatty acids and C20:1 and C22:1 fatty alcohols (Miwa et al., 1971). As a result jojoba oil has a much lower freezing point around $6{ }^{\circ} \mathrm{C}$ and is more suitable for applications like transmission and hydraulic fluids where a lower viscosity is required but protection against premature wear is less of a concern.

Jojoba has been the main natural source of wax esters for commercial applications since the global ban on whale hunting was introduced in 1972. However, as described above jojoba oil is not suitable for all lubricating applications. In addition, the high price of jojoba oil has limited its use which is currently restricted to medical and cosmetics applications as a basis for ointments, creams, and other personal care products. The market for lubricants in Europe alone is about 7 million tons yearly and globally about 50 million tons (Stymne et al., 2013). Today, wax esters are mainly produced chemically from mineral oil or by biotechnological processes employing immobilized lipases (Hills et al., 2003). However, even the lipasebased biotechnological wax ester production depends on fatty alcohols as substrates, which at present must be synthesized chemically. Thus, there is still a strong demand for cheap spermaceti or jojoba-like wax esters completely produced from inexpensive renewable sources like plant fatty acids.

In principle, only two types of enzymes activities are required to produce wax esters in the cells of any organism: Fatty 
Acid Reductases (FAR) catalyse the reduction of fatty acids to primary fatty alcohols and Wax Synthases (WS) esterify the fatty alcohols produced to fatty acids. Interestingly, both enzymes use acyl-CoA substrates and therefore do not directly compete with enzymes involved in TAG assembly which primarily use glycerolipid linked fatty acid substrates. Coexpression of the jojoba FAR and WS genes with a jojoba fatty acid elongase (ScFAE) in Arabidopsis was reported to result in significant accumulation of wax esters in seed oil (Lardizabal et al., 2000), however, this promising result was not followed on by the authors. More recently, Heilmann et al. co-expressed an endoplasmic reticulum (ER)-localized mouse WS with a mouse peroxisomal FAR re-targeted to the ER to generate wax esters in Arabidopsis seeds with principally C18 and C20 fatty acid and fatty alcohol components (Heilmann et al., 2012). The authors reported that linking theses enzymes at their amino-termini to oleosin, an oil body structural protein, wax ester contents as high as $45 \mu \mathrm{g} / \mathrm{mg}$ seed weight or $\sim 15 \%$ of the total seed oil were achieved. Furthermore, expression of these mouse enzymes in an Arabidopsis fad2/fae1 mutant that has high levels of oleic acid in its seeds resulted in wax esters highly enriched in oleoyl alcohol and oleic acid moieties with over $65 \%$ oleyl-oleate accumulated. Work carried out in our laboratory recently demonstrated the feasibility of producing significant amounts of wax ester in the seeds of transgenic Camelina. By co-expressing FAR and WS genes from a range of organisms with enzyme activities which modulate the common acyl-CoA substrate pool for these two enzymes (e.g. FatB and FAE1) we were able to generate a number of transgenic camelina lines accumulating very different types of waxes in their seeds including spermaceti and jojoba-like waxes (unpublished data).

\subsection{Oil production in vegetative tissue for high-energy feed or fuel production}

Due to their high energy density and modifiable chemical composition plant produced oils provide an attractive sustainable alternative to non-renewable fossil sources for fuel and chemical feedstock production (Hill et al., 2006; Dyer et al., Dyer). However, despite a dramatic increase in vegetable oil production in the last decade, limitations on arable land mean that it will be difficult to match the world's fast growing demand for renewable oils with current oilseed crops ( $\mathrm{Lu}$ et al., 2011). High biomass crops engineered for increased lipid content in vegetative tissues have been proposed as a novel platform for meeting global production needs for lowcost, energy-dense lipids (Carlsson et al., 2011; Chapman et al., 2013; Dyer et al., 2012). Although seeds and some fruit pericarps (e.g. palm, olive and avocado) are by far the largest source of plant produced oils, many other tissues are capable of synthesising triacylglycerols and a number of studies reported the presence of cytosolic lipid droplets in the leaf mesophyll cells of many plant species (Lersten et al., 2006; Lin and Oliver 2008). TAGs notably accumulate during senescence in leaves (Kaup et al., 2002), under stress (Sakaki et al., 1990) and in Arabidopsis mutants disrupted in ER to chloroplast lipid trafficking (Xu et al., 2005). Nevertheless, the oil content of vegetative tissues is typically very low in the majority of plant species, particularly in photosynthetic tissues, representing less than $0.2 \%$ of dry weight in leaves (Kelly et al., 2013; Vanhercke et al., 2013).

The possibility of producing TAGs in leaves and other vegetative tissues has recently attracted considerable interest and several studies demonstrated that TAG accumulation can be increased by ectopic expression of individual biosynthetic or regulatory genes involved in seed development and storage lipids metabolism (For review see Napier et al., 2014). However, in most of these single gene studies increases in TAG leaf content was only very modest and/or dependent on the supply of carbohydrates. Since key enzymes for both oil synthesis and breakdown are expressed in vegetative tissue it was suggested that achieving substantial levels of storage lipid in leaf biomass requires the re-direction of carbon flux from other storage compounds, such as starch and proteins, into TAG. This hypothesis was supported initially by the additional effect observed while overexpressing Leafy Cotyledon 2 (LEC2) transcription factor in the $c t s 2 \beta$-oxidation mutant (Slocombe et al., 2009). Recently, industrially relevant levels of storage lipids in vegetative tissue (exceeding $15 \%$ of dry weight) have been achieved via integrated metabolic approaches (so called 'Push, Pull and Protect'). These consisted in redirecting the flux of carbon into TAG manipulating fatty acid synthesis (Push), TAG assembly (Pull) and lipid turnover (Protect) (Kelly et al., 2013; Vanhercke et al., 2013). Lately, the identification of a new class of protein involved in the binding and stabilization of non-seed lipid droplets has provided new insights on the cellular machinery regulating the packaging of triacylglycerol in plant vegetative tissue (Horn et al., 2013). It will be interesting to investigate whether oil accumulation in green biomass can be further improved without severely impacting photosynthesis and plant development. One possibility for achieving this could be the use of senescence induced promoters to engineer plants in which TAG accumulation is initiated only after leaves have reached their maximum size (Durrett et al., 2008). Nevertheless, achieving levels of accumulations matching those observed in seeds (able to accumulate more than 45-50\% TAG, dry weight) remains a great challenge for metabolic engineering. However, this may not be necessary since achieving $15 \%$ (w/w, dry weight) in a high biomass crop such as miscanthus producing an average dry weight of $22 \mathrm{t} / \mathrm{ha}$, would translate in an oil yield of $3.3 \mathrm{t} / \mathrm{ha}$ which is far greater than that obtained with elite oilseed rape cultivars.

The synthesis and accumulation of oil in vegetative tissue may be exploited as a part of an overall strategy to maximise the recovery of renewable resources from agricultural products (Ohlrogge et al., 2009). Indeed, increasing the overall lipid content of crops could have a number of commercially useful applications. In biomass crops the resulting enhanced energy density would make electricity production via combustion more efficient and in forage crops it would beneficially increase the calorie content for livestock nutrition (Kelly et al., 2013). This concept could also be applied to food crops to convert unharvested agricultural waste into valuable co-products for high energy feed or fuel production. Interestingly, it was suggested that the production of TAGs in green biomass could provide an easy way to compartmentalise the biosynthesis of oils intended for industrial purposes in a harvestable location 


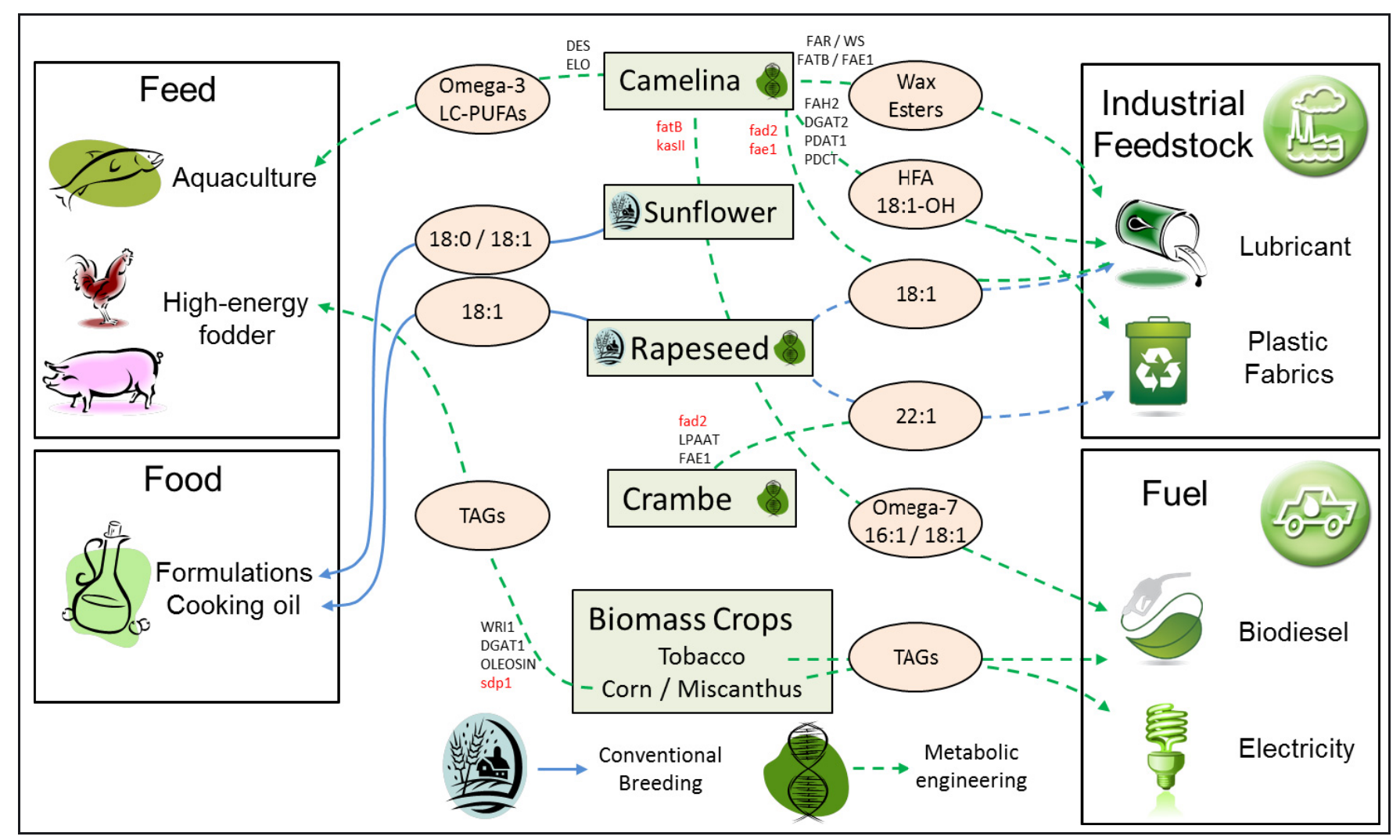

Fig. 1. Schematic representation of some the conventional breeding (Blue arrows) and metabolic engineering (green dashed arrows) strategies used recently to manipulate plant oil composition. Target lipids and fatty acids enriched in the oil as a result of these manipulations are indicated (pink ovals background). Possible utilisation of the resulting oils for food, feed, fuel or as industrial feedstock are also indicated. Black: target genes overexpressed; Red: target genes inactivated by mutation or using a RNAi construct. The Blue dashed arrow used for Rapeseed oil enriched in 22:1 illustrates that both conventional breeding and metabolic engineering approached have been used to achieve this oil quality. 16:1 Palmitoleic acid; 18:1 Oleic acid; 18:1-OH Ricinoleic acid; 22:1 Erucic acid; LC-PUFA: Long chain polyunsaturated fatty acid; HFA: Hydroxy fatty acid; TAG: Triacylglycerol. A color figure is available at: www.ocl-journal.org.

outside the seed (James et al., 2010). Production of unusual fatty acids could therefore be engineered as a co-product in the green biomass of dual purpose crops, otherwise producing seeds for animal feed or human nutrition. Most research efforts so far have focussed on the manipulation of lipid content in leaves, however other part of the plant might also be considered for oil accumulation, further enhancing total oil content in non-seed crop biomass (Carlsson et al., 2011, Kelly et al., 2013).

All the strategies used to manipulate plant oil composition and described in Section 3 are summarised in Figure 1.

\section{New opportunities for molecular breeding and marker-assisted selection}

\subsection{Exploitation of genetic variation to improve agronomic traits}

As illustrated by the examples discussed above, simple oil traits such as composition of naturally occurring fatty acids can be manipulated by conventional breeding exploiting natural and/or induced genetic variation in mapping populations or diversity collections. This has allowed the development of low (LEAR) or high (HEAR) erucic acid, low glucosinolate and very high oleic/very low PUFA rapeseed cultivars. In contrast, metabolic engineering of unusual or novel oil traits, such as omega-3 LC-PUFAs and wax esters production in seed oil or TAG accumulation in vegetative tissue requires a transgenic approach (Fig. 1). The availability of genomic tools and resources (e.g. EST libraries, genome sequences) as well as the development of molecular markers (e.g. RFLP, AFLP, SSR, SNP) has greatly improved the efficiency of plant breeding. However, despite progress in marker assisted breeding, the improvement of complex traits such as nitrogen use efficiency (NUE), pod shatter, seed size and oil content in oilseed crops remains more challenging as the underlying genetic determinants are still poorly understood. For example, studies using segregating rapeseed populations reported the identification of a large number of Quantitative Trait Loci (QTLs) involved in the control of seed oil content, which is consistent with the polygenic determinism of this trait (Delourme et al., 2006; Qiu et al., 2006). In addition, as most crops are polyploid, the resulting genetic complexity presents a barrier for the translation of knowledge from diploid model species such as $S$. cerevisiae and Arabidopsis into crop improvement. Although QTL mapping has been successful in detecting QTL associated with quantitative traits such as seed oil and glucosinolate 


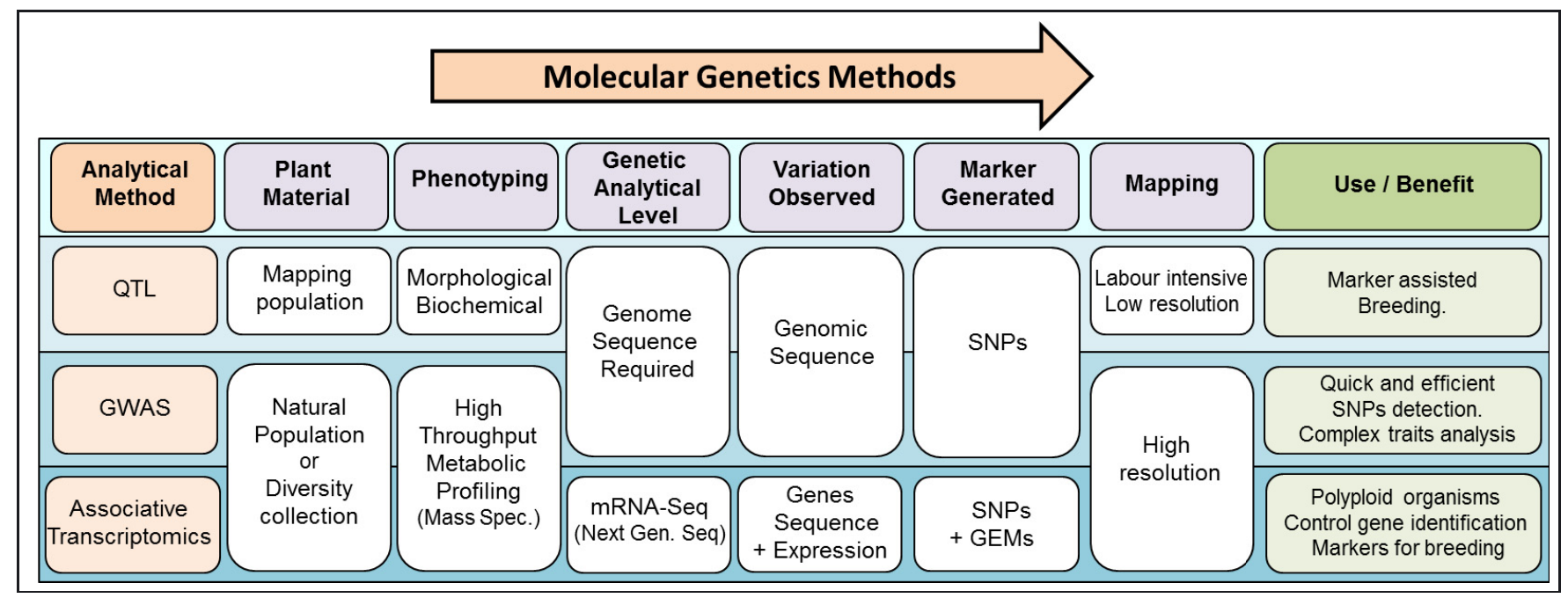

Fig. 2. Classic and novel molecular genetic methods. Exploitation of genetic variation in plant populations to identify and map markers that can be used for plant breeding. Differences between these methods are highlighted. QTL: Quantitative Trait Loci; GWAS: Genome-Wide Association Studies; SNP: Single-Nucleotide Polymorphism; GEM: Gene Expression Marker. A color figure is available at: www.ocl-journal.org.

content, the genetic variation is restricted to the two parents used to generate the mapping population and therefore not always transferable to other material. In addition, fine mapping of QTLs is a laborious and time consuming task which requires a very large population with several thousands of individuals (Fig. 2).

\subsection{Genome wide association studies (GWAS) and associative transcriptomics}

Recently, Association genetics methods have been developed allowing quicker and more efficient identification of association between genetic markers and phenotypic traits in natural populations or panels of genetically diverse lines. Association mapping, also called Linkage Disequilibrium (LD) mapping, exploits the larger number of historical recombination events that have occurred throughout the entire evolutionary history of the mapping population, allowing highresolution QTL mapping (Nordborg and Weigel, 2008). For species with available genome sequences, genome-wide association studies (GWAS) can contribute to the dissection of the genetic architecture of complex agronomic traits (Atwell $\mathrm{et} \mathrm{al}$., 2010; Tian et al., 2001; Zhao et al., 2011) and provide tightly linked markers to aid markers-assisted selection (Fig. 2).

However, undertaking a GWAS requires a large number of polymorphic molecular markers and a genome sequence against which to order them. These requirements are not met for all polyploid crops including extensively cultivated crops such oilseed rape. Recent advances in sequencing and computational technology have enabled the development and efficient assay of large numbers of single-nucleotide polymorphism (SNP) markers across mapping populations, even in polyploids with no reference genome sequences (Trick et al., 2009; Bancroft et al., 2011). These studies focused on the analysis of transcribed sequences (mRNA-Seq), as a means of reducing sequence complexity from that represented by the entire genome. GWAS approaches are limited to the analysis of the variation of gene sequences, whereas mRNA-Seq can additionally be used for the quantification of transcript abundance, which provides functional information including the identification of co-expression networks via methodologies such as Weighted Gene Co-expression Network Analysis (WGCNA; Zhang et al., 2005), which often implicates biochemical pathways, and underpins systems biology approaches. The detection of associations between gene expression variation and trait variation is particularly useful in polyploid organisms, where unequal expression of duplicated genes have been observed (Adams et al., 2003). Thus mRNASeq provides a means to analyse variation for use in GWAS of both gene sequences (as SNP markers) and gene expression (as gene expression markers; GEMs) with a single sequence data set. This technology integrating GWAS, GEM and WGCNA using mRNA-Seq data was named "Associative Transcriptomics" by its inventors (Harper et al., 2012) (Fig. 2). The rationale of this technology is to correlate trait variation with both the quantitative expression of genes and sequence variation of transcripts enabling the application of association genetics in a broad range of crops, even those with complex genomes.

The power of this approach was demonstrated in B. napus by investigating glucosinolate (GSL) content in seed, a complex and environmentally sensitive trait for which the underlying control genes are unknown. Two orthologs of just one A. thaliana gene HAG1 (At5g61420) were identified using a panel of 83 B. napus accessions amongst which 101,644 SNPs were scored and transcript abundance quantified for 125,905 unigenes ordered hypothetically along the 19 B. napus chromosomes (Harper et al., 2012). HAGl is a transcription factor that controls the biosynthesis of aliphatic GSLs which are the type preferentially accumulated in seeds (Hirai et al., 2007). Both orthologs were found missing in the low-GSL accessions which is consistent with being causative of a reduced seed GSL phenotype in $B$. napus. Reduction of seed GSL content is a long lasting target for improvement of rapeseed meal value as fodder. This discovery will be helpful in breeding programs to 
monitor GSL content in the seed without modifying GSL level in other plant organs.

\subsection{New opportunities for enhancement of co-products value in oilseed crops}

In addition to calorie-rich foods, plants produce a wide range of compounds that benefit mankind in terms of health (e.g. essential nutrients) and renewable materials (e.g. vegetable oil). Plant-based (green) industrial biotechnology extends traditional "green biotechnology" (the development of improved plant types) to include the enhancement of coproducts for purification and commercial exploitation, a process often termed "bio-refining".

Oil crops, such as oilseed rape have traditionally been the subject of a very simple bio-refining process, with oil extracted from seeds and protein-rich residues sold for feed. Crop residues, i.e. straw and pod walls, have been discarded. As discussed before in this review, recent advances in metabolic engineering have led to the development of oleaginous crops with novel and high-value oil composition for food and industrial applications. This makes oleaginous crops, particularly rapeseed, obvious targets for green industrial biotechnology to enhance co-product value, with exploitation via a bio-refining approach.

Several potentially economically viable co-products might be bio-refined from the rapeseed crop. However, there are gaps in our knowledge of the control of the accumulation of these compounds, necessitating research into the fundamental science involved. Although many biosynthetic pathways have been studied in species such as A. thaliana, the bases of observed quantitative variation are rarely understood. The problem is much more complex in polyploidy crops such as rapeseed. Taking advantage of recent technological advances such as next generation sequencing and high throughput lipidomic profiling an associative transcriptomics approach can be used to identify the genetic components controlling the quantitative variation observed for traits with potential for bio-refining, and provide molecular tools to enhance the content of these co-products in seeds, but also in non-harvested biomass. In the following two sections we describe examples relevant to Brassica oilseed crops.

\subsubsection{Tocopherol and phytosterols content in seeds}

Tocopherols and phytosterols are lipid-soluble compounds accumulated in the oil of rapeseed, which represents one of the richest sources. The principal forms in rapeseed oil are alpha and gamma isoforms of tocopherol, and sitosterol, campesterol and brassicasterol types of phytosterols. Both groups of compounds have health benefits: tocopherols as dietary antioxidants and phytosterols in food production for lowering LDL cholesterol. They also have emerging industrial/pharmaceutical applications, so demand is growing. For example, tocopherols are attracting increasing interest as thermal stabilisers in melt polymers (e.g. in the production of LLDPE films) and in lubricants intended for sensitive environments such as food production, where they are added to extend the product storage and service life. Around a fifth of phytosterol production is presently going into pharmaceutical production (for steroid-based drugs such as birth-control pills) and cosmetics/personal care products. Neither is required for industrial applications of rapeseed oil, but both are already purified easily as high value co-products from rapeseed oil $(\sim 65 \$ / \mathrm{kg}$ for tocopherol, $\sim 30 \$ / \mathrm{kg}$ for phytosterols; data from Cargill). However, both show inter-varietal differences in amount and type (Marwede et al., 2004; Gül et al., 2007), with the differing types having differing commercial values. The accumulation of both may show some environmental interaction, with yields in current rapeseed varieties typically $\sim 1.3 \mathrm{~kg} / \mathrm{ha}$ for tocopherols and $\sim 4$-fold higher for phytosterols (data from Cargill). Thus added value to the crop is already over $£ 100 /$ ha, with much scope for enhancement by breeding. Although the biosynthetic pathways for the compounds have been studied, and candidate genes have emerged as being possibly of relevance (e.g. orthologues of VTE2 for total tocopherol content, VTE2 and VTE4 for the proportions of alpha and gamma tocopherol), the genetic control of the accumulation of these compounds in rapeseed is unknown. Similarly, very little information is available on the genetic control of phytosterol content in rapeseed. However, two QTL for phytosterol content were found to correlate with the two erucic acid genes (BnaA.FAEl and BnaC.FAE1) in B. napus (Amar et al., 2008). This is consistent with the tight negative correlation observed between erucic acid and phytosterol content in that species. Interestingly, it has been reported that the application of nitrogen fertilisers may also negatively affect phytosterol content in some rapeseed cultivars (Gül et al., 2007).

\subsubsection{Wax and functional polysaccharides from stems and pods}

The stems and pods of most commercially cultivated oilseed rape cultivars are very glaucous because their surface is covered with a very high density of epicuticular wax crystals. The biosynthesis and regulation of cuticular waxes has been extensively studied in A. thaliana (Bernard and Joubes, 2012), but there has been little work carried out in oilseed rape. Epicuticular waxes are readily removed by supercritical $\mathrm{CO}_{2}$, leaving no solvent residues. In B. napus and B. rapa they are present in substantial quantities in crop residues including stems $(\sim 13 \mathrm{~kg} / \mathrm{ha})$ and pods ( $27 \mathrm{~kg} / \mathrm{ha})$ (unpublished data). Alkanes represent up to $50 \%$ of total wax and are composed largely of nonacosane (C29 alkane; 90-96\%) and a small amount of hentriacontane $(\mathrm{C} 31 ; 2-3 \%)$. Alkanols from Brassica wax consist of a mixture of hexacosanol (C26), octacosanol (C28) and triacontanol C30) and represent 3-20\% of total wax depending on the species and organ analysed. Alkanes with 17 to 35 carbon atoms have melting point temperatures ranging from 21 to $75^{\circ} \mathrm{C}$ and form the major components of some lubricants. They also act as anti-corrosive agents, as their hydrophobic nature protects the metal surface from contact with water. Solid alkanes also find use as paraffin wax in candles. In addition, odd numbered alkanes are important semiochemical molecules (Nakashima et al., 2004). The application of wax extracts reduces aphid foraging on important food crops (Powell et al., 1997). In particular, nonacosane 
has been reported to be a component of a pheromone of Orgyia leucostigma and evidence suggests it plays a role in the chemical communication of several insects (El-Sayed, 2014). Polycosanols are used in the treatment of various chronic diseases such as diabetes. They are also used as a nutritional supplement intended to lower LDL cholesterol ("bad" cholesterol), increase HDL cholesterol ("good" or "healthy" cholesterol) and help prevent atherosclerosis (Berthold et al., 2006). The most prevalent alcohol in polycosanols is octacosanol (Ohta et al., 2008) followed by triacontanol. Phytosterols are also used to reduce plasma cholesterol and LDL by interfering with the intestinal absorption of cholesterol originating in the diet. Combinations of polycosanols and phytosterols are claimed to act synergistically (Dartey, 2002). Extraction from Brassica stems and pod valves would provide a low-cost and sustainable source of these valuable molecules.

Functional polysaccharides are exploited commercially in many arenas, both food and non-food (Waldon, 2007). Many sources of Lignocellulosic biomass are rich in non-cellulosic polymers, often comprising pentose-containing hemicelluloses such as xyloglucans, xylans and arabinoxylans (Brett et al., 1996). These have the potential to provide industrially interesting polymers such as high-value stabilisers, surfactants and barriers (Waldron et al. 2008). The cell walls of rape stems contain significant quantities of such components. Variation in the quality characteristics amongst a large number of oilseed rape cultivars (diversity set) can be evaluated and used to identify appropriate genetic targets for breeding more valuable hydrocolloid-containing biomass.

\section{Conclusion}

There are considerable challenges facing the world, including how to produce more biomass for food, feed and fuel without significantly impacting on our environment or increasing our consumption of limited resources such as water or petrochemical-derived carbon. Simply put, this has been described as the need for sustainable intensification. The purpose of this short review has been to highlight not only these challenges, but also shine some light on the potential solutions that can contribute to ensuring that the global population in 2050 is well-provided-for and greener than ever before. It is our hope and belief that modern plant breeding (including biotechnology and genetic modification) combined with effective and sensitive agricultural practises can secure this vision.

\section{References}

Abbadi A, Domergue F, Bauer J, et al. 2004. Biosynthesis of verylong-chain polyunsaturated fatty acids in transgenic oilseeds: constraints on their accumulation. Plant Cell 16: 2734-2748

Adams KL, Cronn R, Percifield R, Wendel JF. 2003. Genes duplicated by polyploidy show unequal contributions to the transcriptome and organ-specific reciprocal silencing. Proc. Natl. Acad. Sci. USA 100: 4649-4654

Amar S, Ecke W, Becker H C, Moellers C. 2008. QTL for phytosterol and sinapate ester content in Brassica napus L. collocate with the two erucic acid genes. Theor. Appl. Genet. 116: 1051-1061.
Atwell S, Huang YS, Vilhjalmsson BJ, et al. 2010. Genome-wide association study of 107 phenotypes in Arabidopsis thaliana inbred lines. Nature 465: 627-631.

Banaś W, Sanchez Garcia A, Banaś A, Stymne S. 2013. Activities of acyl-CoA:diacylglycerol acyltransferase (DGAT) and phospholipid:diacylglycerol acyltransferase (PDAT) in microsomal preparations of developing sunflower and safflower seeds. Planta 237:1627-1636.

Bancroft I, Morgan C, Fraser F, et al. 2011. Genome dissection in the polyploid crop oilseed rape by transcriptome sequencing. Nat. Biotechnol. 29: 762-766.

Bates PD, Johnson SR, Cao X, Li J, Nam JW, Jaworski JG, Ohlrogge JB, Browse J. 2014. Fatty acid synthesis is inhibited by inefficient utilisation of unusual fatty acids for glycerolipid assembly. Proc. Natl. Acad. Sci USA 111: 1204-1209.

Beaudoin F, Michaelson LV, Hey SJ, et al. 2000. Heterologous reconstitution in yeast of the polyunsaturated fatty acid biosynthetic pathway. Proc. Natl Acad. Sci. USA 97: 6421-6426

Bernard A, Joubès J. 2013. Arabidopsis cuticular waxes: advances in synthesis, export and regulation. Prog Lipid Res. 52: 110-129.

Brett CT, Waldron KW. 1996. Physiology and biochemistry of plant cell walls. 2e ed. Chapman and Hall.

Berthold HK, Unverdorben S, Degenhardt R. Bulitta M, GouniBertold I. 2006. Effect of policosanol on lipid levels among patients with hypercholesterolemia or combined hyperlipidemia. $J$. Amer. Med. Assoc. 295: 2262-2269.

Carlsson AS. 2009. Plant oils as feedstock alternatives to petroleum - A short survey of potential oil crop platforms. Biochimie 91: 665-670

Carlsson AS, Lindberg Yilmaz J, Green AG, Stymne S, Hofvander P. 2011. Replacing fossil oil with fresh oil-with what and for what? Eur. J. Lipid Sci. Technol. 113: 812-831.

Chapman K, Dyer JM, Mullen RT. 2013. Why don't plant leaves get fat? Plant Sci. 207: 128-134.

Dartey CK. 2002. Long-chain alcohols admixed in sterol compounds. European Patent EP 1108364 A3

Delourme R, Falentin C, Huteau V, et al. 2006. Genetic control of oil content in oilseed rape (Brassica napus L.). Theor. Appl. Genet. 113: 1331-1345.

Domergue F, Abbadi A, Ott C, Zank TK, Zahringer U, Heinz E. 2003. Acyl carriers used as substrates by the desaturases and elongases involved in very long-chain polyunsaturated fatty acids biosynthesis reconstituted in yeast. J. Biol. Chem. 278: 35115-35126

Domergue F, Abbadi A, Zahringer U, Moreau H, Heinz E. 2005. In vivo characterization of the first acyl-CoA D6-desaturase from a member of the plant kingdom, the microalga Ostreococcus tauri. Biochem. J. 389: 483-490.

Durrett TP, Benning C, Ohlrogge J. 2008. Plant triacylglycerols as feedstocks for the production of biofuels. Plant J. 54: 593-607.

Dyer JM, RT Mullen. 2005. Development and potential of genetically engineered oilseed crops. Seed. Sci. Res. 15: 255-267

Dyer JM, Mullen RT. 2008. Engineering plant oils as high-value industrial feedstocks for biorefining: the need for underpinning cell biology research. Physiol. Plant. 132: 11-22.

Dyer J, Mullen R, Chapman K. 2012. Oil in biomass: a step-change for bioenergy production? Inform. 23: 193-272.

Eckert H, LaVallee B, Schweiger BJ, Kinney AJ, Cahoon EB, Clemente T. 2006. Co-expression of the borage D6 desaturase and the Arabidopsis $\Delta 15$ desaturase results in high accumulation of stearidonic acid in the seeds of transgenic soybean. Planta 224: 1050-1057.

El-Sayed AM. 2014. The Pherobase: Extensive database of insect pheromones and semiochemicals. Available at: http://www. pherobase.com. 
Van Erp H, Bates PD, Shockey J, Burgal J, Browse J. 2011. Castor phospholipid:diacylglycerol acyltransferase facilitates efficient metabolism of hydroxyl fatty acids in transgenic Arabidopsis. Plant Physiol. 155: 683-693.

Guan R, Lager I, Li X, Stymne S, Zhu L-H. 2014. Bottlenecks in erucic acid accumulation in genetically engineered ultrahigh erucic acid Crambe abyssinica. Plant Biotech. J. 12: 193-203

Gül M, Egesel C, Tayyar S, Kahirman F. 2007. Changes in phytosterols in Rapeseed (Brassica napus L.) and their interaction with nitrogen fertilisation. Int. J. Agri. Biol. 9: 250-253.

Harper AL, Trick M, Higgins J, Fraser F, Clissold L, Wells R, et al. 2012. Associative transcriptomics of traits in the polyploid crop species Brassica napus. Nat. Biotechnol. 30: 798-802.

Haslam RP, Ruiz-Lopez N, Eastmond P, Moloney M, Sayanova O, Napier JA. 2012. The modification of plant oil composition via metabolic engineering-better nutrition by design. Plant Biotech. J. 11: 157-168

Heilmann M, Iven T, Ahmann K, Hornung E, Stymne S, Feussner I. 2012. Production of wax esters in plant seed oils by oleosomal cotargeting of biosynthetic enzymes. J. Lipid Res. 5: 2153-2161.

Hills G. 2003. Industrial use of lipases to produce fatty acid esters. Eur. J. Lipid Sci. Technol. 105: 601-607.

Hill J, Nelson E, Tilman D, Polasky S. Tiffany D. 2006. Environmental, economic, and energetic costs and benefits of biodiesel and ethanol biofuels. Proc. Natl. Acad. Sci. USA 103: 11206-11210.

Hirai MY, Sugiyama K, Sawada Y, et al. 2007. Omics-based identification of Arabidopsis Myb transcription factors regulating aliphatic glucosinolate biosynthesis. Proc. Natl. Acad. Sci. USA 104: 6478-6483.

Hong H, Datla N, Reed DW, Covello PS, MacKenzie SL, Qiu X. 2002. High-level production of c-linolenic acid in Brassica juncea using a $\Delta 6$ desaturase from Pythium irregulare. Plant Physiol. 129: 354-362.

Horn PJ, James CN, Gidda SK, et al. 2013. Identification of a new class ofdroplet associated proteins in plants. Plant Physiol. 162: $1926-1936$

James CN, Horn PJ, Case CR, et al. 2010. Disruption of the Arabidopsis CGI-58 homologue produces Chanarin-Dorfmanlike lipid droplet accumulation in plants. Proc. Natl. Acad. Sci. USA 107: 17833-17838.

Julie-Galau S, Bellec Y, Faure J.-D, Tepfer M. 2014. Evaluation of the potential for interspecific hybridization between Camelina sativa and related wild Brassicaceae in anticipation of field trials of GM camelina. Transgenic Res. 23: 67-74.

Kagale S, Koh C, Nixon J, Bollina V, Clarke W, Tuteja R, Spillane C, Robinson S, Links M, Clarke C, Higgins E, Huebert T, Harpe A, Parkin I. 2014. The emerging biofuel crop Camelina sativa retains a highly undifferentiated hexaploid genome structure. Nat. Commun. 5: 3706.

Kalscheuer R, Stoveken T, Luftmann H, Malkus U, Reichelt R, Steinbuchel A. 2006. Neutral lipid biosynthesis in engineered Escherichia coli: Jojoba oil-like wax esters and fatty acid butyl esters. Appl. Environ. Microbiol. 72: 1373-1379.

Kang J, Snapp AR, Lu C. 2011. Identification of three genes encoding microsomal oleate desaturases (FAD2) from the oilseed crop Camelina sativa. Plant Physiol. Biochem. 49: 223-229.

Kaup MT, Froese CD, Thompson JE. 2002. A role for diacylglycerol acyltransferase during leaf senescence. Plant Physiol. 129: 16161626.

Kelly AA, van Erp H, Quettier AL, et al. 2013. The SUGARDEPENDENT1 lipase limits triacylglycerolsaccumulation in vegetative tissues of Arabidopsis. Plant Physiol. 162: 1282-1289.
Lardizabal KD, Metz JG, Sakamoto T, Hutton WC, Pollard MR, Lassner MW. 2000. Purification of a Jojoba embryo wax synthase, cloning of its cDNA, and production of high levels of wax in seeds of transgenic Arabidopsis. Plant Physiol. 122: 645-656.

Lersten NR, Czlapinski AR, Curtis JD, Freckmann R Horner HT. 2006. Oil bodies in leaf mesophyll cells of angiosperms: overview and a selected survey. Am. J. Bot. 93: 1731-1739.

Lin W, Oliver DJ. 2008. Role of triacylglycerols in leaves. Plant Sci. 175: 233-237.

Li XN, van Loo E, Gruber J, et al. 2012. Development of ultra-high erucic acid oil in the industrial oil crop Crambe abyssinica. Plant Biotech. J. 10: 862-870.

$\mathrm{Lu} \mathrm{C}$ and Kang J. 2008. Generation of transgenic plants of a potential oilseed crop Camelina sativa by Agrobacterium-mediated transformation. Plant. Cell Rep. 27: 273-278.

Lu C, Napier JA, Clemente TE, Cahoon EB. 2011. New frontiers in oilseed biotechnology: meeting the growing global demand for vegetable oils for food, feed, biofuel, and industrial uses. Curr. Opin. Biotechnol. 22: 252-259.

Marwede V, Schierholt A, Mollers C, Becker HC. 2004. Genotype x environment interactions and heritability of tocopherols content in canola. Crop Sci. 44: 728-731.

Meyer A, Kirsch H, Domergue F, et al. 2004. Novel fatty acid elongases and their use for the reconstitution of docosahexaenoic acid biosynthesis. J. Lipid Res. 45: 1899-1909

Miwa TK. 1971. Jojoba oil wax esters and derived fatty acids and alcohols: gas chromatographic analyses. J. Am. Oil Chem. Soc. 48: 259-264.

Nakashima Y, Birkett MA, Pye BJ, Pickett JA, Powell W. 2004. The role of semiochemicals in the avoidance of the seven-spot ladybird, Coccinella septempunctata, by the aphid parasitoid, Aphidius ervi. J. Chem. Ecol. 30: 1103-1116.

Nath N, Wilmer J, Wallington E, Becker H, Mollers C. 2009. Increasing erucic acid content through combination of endogenous low polyunsaturated fatty acid alleles with Ld-LPAAT + Bn-FAE1 transgenes in rapeseed. Theor. Appl. Genet. 118: 795773.

Napier JA. 2007. The production of unusual fatty acids in transgenic plants. Annu. Rev. Plant Biol. 58: 295-319

Napier JA, Haslam RP, Beaudoin F, Cahoon EB. 2014. Understanding and manipulating plant lipid composition: metabolic engineering leads the way. Curr. Opin. Plant Biol. 19: 68-75.

Nguyen H, Silva J, Podicheti R, et al. 2013. Camelina seed transcriptome: a tool for meal and oil improvement and translational research. Plant Biotechnol. J. 11: 759-769.

Nguyen H, Park H, Koster K, et al. 2014. Redirection of metabolic flux for high levels of omega-7 monounsaturated fatty acid accumulation. Plant Biotechnol. J. doi 10.1111/pbi.12233.

Nordborg M, Weigel D. 2008. Next-generation genetics in plants. Nature 456: 720-723.

Ohlrogge J, Allen D, Berguson B, Dellapenna D, Shachar-Hill Y and Stymne S. 2009. Energy. Driving on biomass. Science 324: 10191020

Ohta Y, Ohashi K, Matsura T, Tokunaga K, Kitagawa A, Yamada K. 2008. Octacosanol attenuates disrupted hepatic reactive oxygen species metabolism associated with acute liver injury progression in rats intoxicated with carbon tetrachloride. J. Clin. Biochem. Nutr. 42: 118-25.

Petrie JR, Shrestha P, Belide S, et al. 2014. Metabolic engineering Camelina sativa with fish oil-like levels of DHA. PLoS One 9: e85061.

Powell G. Hardie J, Pickett JA. 1997. Laboratory evaluation of antifeedant compounds for inhibiting settling by cereal aphids. Entomol. Exp. Appl. 84: 189-193. 
Qiu D, Morgan C, Shi J, et al. 2006. A comparative linkage map of oilseed rape and its use for QTL analysis of seed oil and erucic acid content. Theor. Appl. Genet. 114: 67-80.

Ruiz-Lopez N, Haslam R, Napier JA, Sayanova O. 2014. Successful high-level accumulation of fish oil omega-3 long-chain polyunsaturated fatty acids in a transgenic oilseed crop. Plant J. 77: 198-208.

Sakaki T, Kondo N, Yamada M. 1990. Pathway for the synthesis of triacylglycerols from monogalactosyldiacylglycerols in ozonefumigated spinach leaves. Plant Physiol. 94: 773-780.

Salas J, Martínez-Force E, Harwood J, et al. 2014. Biochemistry of high stearic sunflower, a new source of saturated fats. Progress Lipid Res. 55: 30-42.

Sato S, Xing A, Ye X, et al. 2004. Production of c-linolenic acid and stearidonic acid in seeds of marker-free transgenic soybean. Crop Sci. 44: 646-652.

Sayanova O, Ruiz-Lopez N, Haslam RP, Napier JA. 2011. The role of D6-desaturase acyl-carrier specificity in the efficient synthesis of long-chain polyunsaturated fatty acids in plants. Plant Biotechnol. J. 10: 195-210.

Slocombe SP, Cornah J, Pinfield-Wells H, Soady K, Zhang Q, Gilday A. 2009. Oil accumulation in leaves directed by modification of fatty acid breakdown and lipid synthesis pathways. Plant Biotechnol. J. 7: 694-703.

Snapp AR, Kang J, Qi X, Lu C. 2014. A fatty acid condensing enzyme from Physaria fendleri increases hydroxyl fatty acid accumulation in transgenic oilseeds of Camelina sativa. Planta 240: 599-610.
Stymne S. 2013. ICON (Industrial Crops producing added value Oils for Novel chemicals), Periodic Report 3.

Tian F, Bradbury P, Brown P, et al. 2011. Genome-wide association study of leaf architecture in the maize nested association mapping population Nat. Genet. 43: 159-162

Trick M, Long Y, Meng J, Bancroft I. 2009. Single nucleotide polymorphism (SNP) discovery in the polyploid Brassica napus using Solexa transcriptome sequencing. Plant Biotechnol. J. 7: 334346.

Vanhercke T, El Tahchy A, Liu Q, et al 2013. Metabolic engineering of biomass for high energy density: oilseed-like triacylglycerol yields from plant leaves. Plant Biotechnol. J. 12: 231-239

Waldron KW. 2007. Handbook of waste management and co-product recovery in food processing (Volume 1) CRC Press.

Waldron KW, et al. 2008. patent GB2442954A

Wells R, Trick M, Soumpourou E, et al. 2014. The control of seed oil polyunsaturate content in the polyploid crop species Brassica napus. Mol. Breed. 33: 349-362.

Xu C, Fan J, Froehlich JE, Awai K, Benning C. 2005. Mutation of the TGD1 chloroplast envelope protein affects phosphatidate metabolism in Arabidopsis. Plant Cell 17: 3094-3110.

Zhang B, Horvath S. 2005. A general framework for weighted gene co-expression network analysis. Stat. Appl. Genet. Mol. Biol. 4: 17.

Zhao K, Tung C, Eizenga G, et al. 2011. Genome-wide association mapping reveals a rich genetic architecture of complex traits in Oryza sativa. Nat. Commun. 2: 467.

Cite this article as: Frédéric Beaudoin, Olga Sayanova, Richard P. Haslam, Ian Bancroft, Johnathan A. Napier. Oleaginous crops as integrated production platforms for food, feed, fuel and renewable industrial feedstock. OCL 2014, 21(6) D606. 